\title{
The control of colour by using measurement and feedback
}

\section{Document Version}

Accepted author manuscript

Link to publication record in Manchester Research Explorer

\section{Citation for published version (APA):}

Oulton, D. P., \& Porat, I. (1992). The control of colour by using measurement and feedback. Journal of the Textile Institute, 83(3), 454-461.

\section{Published in:}

Journal of the Textile Institute

\section{Citing this paper}

Please note that where the full-text provided on Manchester Research Explorer is the Author Accepted Manuscript or Proof version this may differ from the final Published version. If citing, it is advised that you check and use the publisher's definitive version.

\section{General rights}

Copyright and moral rights for the publications made accessible in the Research Explorer are retained by the authors and/or other copyright owners and it is a condition of accessing publications that users recognise and abide by the legal requirements associated with these rights.

\section{Takedown policy}

If you believe that this document breaches copyright please refer to the University of Manchester's Takedown Procedures [http://man.ac.uk/04Y6Bo] or contact uml.scholarlycommunications@manchester.ac.uk providing relevant details, so we can investigate your claim.

\section{OPEN ACCESS}




\title{
The Control of Colour by Using Measurement and Feedback
}

\author{
D.P. Oulton and I. Porat \\ Department of Textiles, University of Manchester Institute of Science and Technology, \\ Manchester 1, England
}

Received 22.5.1992 Accepted for publication 24.6.1992

Colour simulation on CAD computer screens is a potentially important aid to rapid response in product development. Control of screen colour in high-resolution CRT monitors can be achieved on the basis of the principles of additive colour-mixing. The use of trichromatic-unit colour specifications is extended to include RGB drive values and provide a measured feedback signal for correcting colour. Measurement and feedback control are shown to be successful and are employed in the Shademaster CAD system for colour-range development.

\section{INTRODUCTION}

Reproduction of colour to exact specifications is a major preoccupation of the textile industry. This is particularly true of the rapidly growing computer-aided-design (CAD) sector. Here designs are simulated on a computer screen in full colour, and a variety of tools is provided for selecting and manipulating colour on screen. Unfortunately, screen colour is not stable or reproducible unless steps are taken to calibrate and control it.

Most current CAD systems use uncalibrated colour. In consequence, designers are unable to define or communicate accurately any pleasing effect that they produce on the computer screen. This limits colour to a simple illustrative role. By contrast, a system with calibrated colour gives precise definitions for all colours seen. They can then be reproduced on other screens, as hard-copy print-outs, and in textile production.

The numerical specifications for colour used in current CAD systems are expressed in terms of red, green, and blue (RGB) or hue, value, and saturation (HVS) combinations. Both refer to gun-drive values, and the colour specified varies over time, depending on the current state of the monitor screen. It also varies from monitor to monitor, depending on type, age, and adjustment.

By contrast, the CIE system of colour specification [1] is independent of any specific reproduction system and is widely used to specify colour in textile manufacture. Colorimeters and spectrophotometers are available for measuring the CIE specification of both screen colours and textile materials. CIE specifications were thus chosen as the ideal method of specifying screen colour, so that it can be readily communicated to those who need to examine and implement a designer's colour ideas.

The Control of Colour by Using Measurement and Feedback 
The problem addressed is how to calibrate a monitor screen so that its colour is precisely defined in terms of CIE co-ordinates. Several different approaches have been tried by other workers in the field. In one, quite widely adopted, approach, a fixed CIE XYZ-to-RGB conversion and a stabilized monitor are used. Another system uses elaborate calibration routines, involving thousands of measurements, but does not address the day-to-day, hour-to-hour, or long-term changes in monitor performance.

In this paper, we introduce a feedback-and-control system which maintains a dynamic $X Y Z$-to-RGB conversion that takes into account the current state of the monitor.

The CIE co-ordinates of the screen are measured with a Minolta CA100 colour analyzer, interfaced to the computer which is driving the screen. This provides feedback information for use by an 'Adaptive Driver' system, which maintains an adaptable mapping for $X Y Z$-to-RGB conversions.

Additive-mixing theory has been successfully applied to the problem, giving a calibration sequence lasting a few minutes, and using a minimum of calibration points. The system can be employed with a wide range of standard monitors.

The work reported here shows that such a feedback-and-control system can maintain screen colour to precise specification and compensate for both short- and longterm changes in monitor characteristics.

\section{PRINCIPLES OF MONITOR CONTROL}

\subsection{Colour-reproduction Control}

The papers of Cowan and Rowel [2], Post and Calhoun [3], and Hawkyard and Oulton [4] have shown that it is possible to transform CIE colour specifications into RGB gundrive values for a high-resolution colour monitor. The resulting screen colour is a close visual match to a surface colour provided that they have the same CIE coordinates to within a AE (CMC 2: I) of 1.5-2.0 and care is taken to set the screen colour in an appropriate visual context [4].

Standard transformations [3] of CIE XYZ specifications to gun-drive RGB values do not take account of the fact that monitor colour varies over a substantial range in the first hour from switch-on and as the tube ages or goes out of adjustment.

The principles of additive RGB mixing to produce specified colours are well described by Sproson [5]. In order to provide the fine control required, the screen colour needs to be measured accurately and the RGB drive characteristics altered until the screen reproduces the desired $\mathrm{CIE}$ colour specification.

As a typical high-resolution colour monitor is capable of displaying $256^{3}=16.77$ million RGB combinations, it is necessary to use additive-mixing theory to reduce the calibration problem to manageable proportions.

Sproson [5] shows that CIE XYZ colour specifications can be transformed exactly into RGB specifications provided that both are expressed in trichromatic units (T-units),

The Control of Colour by Using Measurement and Feedback 
i.e. units of colour which have the same relative effect on mixtures. Thus, $1 \mathrm{~T}$-unit each of $R, G$, and $B$ always produces a neutral when mixed, and, by additive principles [6], so does a 10:10:10 mixture.

This both simplifies the calibration problem enormously and provides the necessary feedback mechanism to control the gun drives. All that is required is to ensure that at any time the red, green, and blue guns will deliver trichromatic-unit quantities of the appropriate phosphor colour as indicated by the $X Y Z$-to-RGB T-unit calculations.

The relationship between T-unit quantities and numerical-drive values is not only non -linear: it also varies with the nature of the phosphor being excited by the electron beam. It further appears to vary significantly with age, temperature, and other internal monitor variables, and with the variables associated with digital-to-analog conversion in the graphics subsystem which drives the monitor.

Control thus depends on balancing three non-linear functions simultaneously:

$$
\left.\begin{array}{l}
R_{G u n}=f\left(R_{T}\right) \\
G_{G u n}=f\left(G_{T}\right) \\
B_{G u n}=f\left(B_{T}\right)
\end{array}\right\}
$$

where $R_{T}, G_{T}$, and $B_{T}$ are $T$-unit colour specifications produced by the matrix transformation from $\mathrm{CIE} X Y Z$ specifications.

\subsection{The Feedback Signal}

We now need to produce a signal that indicates an $R_{T}, G_{T} B_{T}$ balance on the screen and deviations from balance.

The principle is as follows.

(i) The CIE colour specification ( $X Y Z)$, which is in T-units, is calculated for a given illuminant, usually artificial daylight, D65.

(ii) D65 has known co-ordinates $(x=0.313, y=0.329)$, and a perfect neutral surface has the same co-ordinates.

Thus perfect $R_{T}, G_{T} B_{T}$ balance is indicated by a screen chromaticity of $x=0.313, y=$ 0.329 .

The required feedback signal is then given by the screen co-ordinates of a set of neutrals from full gun drive, 255, 255, 255 down to near black, say, 20, 20, 20.

\subsection{Gun-drive Correction}

Not only must the three functions of Equation (1) be balanced at all levels; they must also have the correct over-all shape. This is necessary so that $1 \mathrm{~T}$-unit change in, say, blue has the same effect on mixtures when present at low intensity as when it is present at high intensity.

The Control of Colour by Using Measurement and Feedback 
The correct over-all curve shape is given by the CIE $Y$ curve, which is itself expressed in T-units.

Full gun-drive correction can thus be achieved simultaneously at a series of selected calibration points by:

(a) balancing R, G, and B drive values until a neutral balance is achieved; and

(b) raising or lowering all three until the over-all $Y$ value of the screen is at the correct value for the selected calibration point.

A matrix relationship is used to relate deviations of balance $\mathrm{d} X, \mathrm{~d} Y, \mathrm{~d} Z$ to required changes in gun value $d R, d G, d B$.

It is necessary to use a repetitive measure/correct (iterative) loop to achieve the desired balance.

\subsection{Calibration and Specification of Screen Colour}

For a full calibration system, it is necessary to turn any decimal CIE $X Y Z$ colour specification into its equivalent gun-drive values. A set of calibration points is thus required on each of the three curves of Equation (1). It has been found in practice [4] that from twelve to twenty points are sufficient to provide accurate interpolation of all possible gun values from T-unit specifications. Thus, by calibrating at a very few points in colour space, the whole 16.77 million possible combinations can be accurately predicted.

Theory predicts that, provided that strict T-unit quantities of $R, G$, and $B$ are mixed, then the colour will be reproduced with exactly the correct specification on screen. The second part of this paper shows that a very successful CAD system for colour has been developed at UMIST on the basis of these principles.

\subsection{Breakdown of Additivity}

The literature on monitor calibration described above and Rich's paper [7] all consider monitor calibration to be a difficult problem, and many potential causes of additivity breakdown are identified. Whereas these are undoubtedly important, the correct identification of a suitable feedback signal and its application to gun-drive correction are shown below to produce a significant improvement in colour control.

It is clear both from the literature and from work at UMIST that two problems are important in maintaining a good level of additivity. These are:

(i) gun independence, and

(ii) screen-contents independence.

In a well-adjusted colour monitor, excitation of one phosphor leaves the others at minimal emission. i.e. gun independence operates. Further, a high beam current to one colour must not affect the beam current available for either of the other colours.

Screen-contents dependence occurs where the combined beam current (electron stream density) is deliberately limited in the monitor. This is done to prevent distortion of the shadow mask. which ensures beam registration, i.e., gun independence.

The Control of Colour by Using Measurement and Feedback 
We have found that very few monitors are satisfactory under these criteria. The best are those based on Trinitron technology (Sony, Eizo, etc.).

\section{A PRACTICAL COLOUR-REPRODUCTION SYSTEM}

\subsection{Control and Feedback in Practice}

The control-and-feedback mechanism described above is implemented in the UMIST 'Adaptive Driver' system (Fig. 1). This allows screen colours to be specified by their CIE D65 2-deg observer XYZ co-ordinates [1].

The feedback loop covers the whole process of generating the R, G, B T-unit specifications. including the digital-to-analog conversion in the computer's graphics subsystem. Some other monitor-calibration systems, such as the Barco systems, which is an example of the stabilized monitors described earlier, limit control to within the monitor and do not control the full conversion.

\section{Figure 1}

\section{THE ADAPTIVE DRIVER SYSTEM}

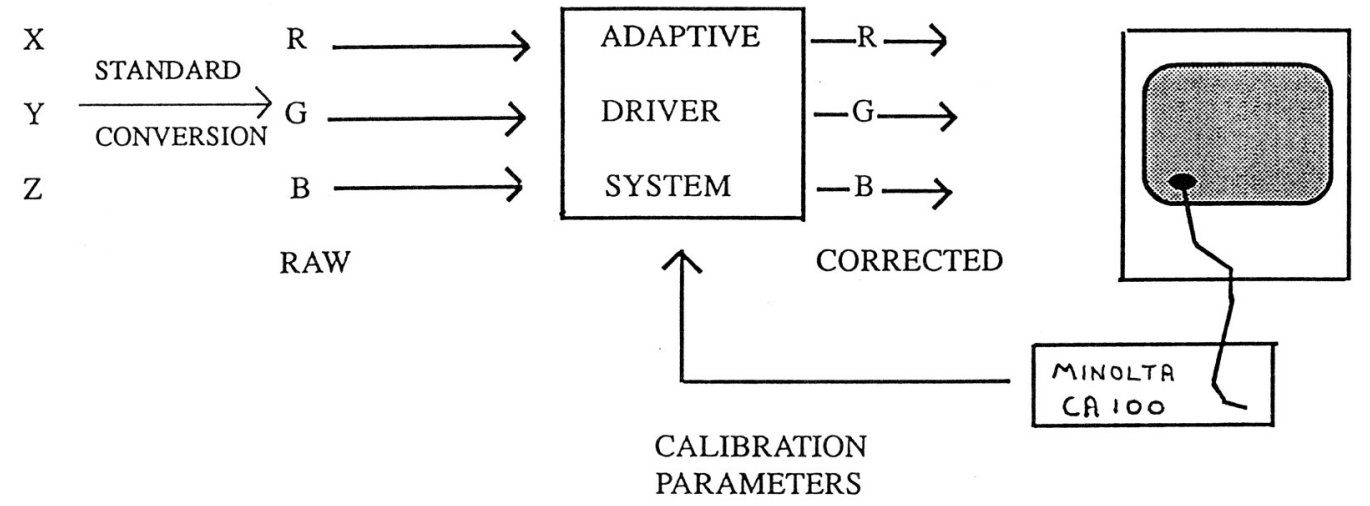

IN LEARN MODE :-

THE ADAPTIVE DRIVER USES CHROMATICITY AND LUMINANCE

TO LEARN THE CORRECT LUMINANCE CURVE FOR EACH GUN AT ALL LEVELS

IN CALIBRATION MODE :-

THE ADAPTIVE DRIVER USES LUMINANCE OF SINGLE GUNS TO ADJUST R G \& B DRIVE CHARACTERISTICS UNTIL SCREEN OUTPUT IS BACK TO NOMINAL.

IN USE :-

INPUT $x, y, Y$ SPECIFICATIONS ARE CONVERTED TO CORRECTED R G BS USING THE LATEST CALIBRATION DATA

Calibration by means of the Adaptive Driver takes from about three to five minutes, and, provided that the monitor is allowed to 'warm up' for about 30 minutes, a calibration is produced which holds good for at least half a day. During warm up, an accurate calibration can be produced, but recalibration is then necessary within half an hour. 
In order to quantify the accuracy of calibration, a set of 40 test colours is used. They are all standard Munsell colours [1] and there are four groups:

Group 1: 10 neutrals of Munsell values 1-10;

Group 2: 10 pale shades, value 8, chroma 6, forming a hue circle;

Group 3: 10 medium shades, value 5, chroma 6, forming a hue circle;

Group 4: 10 dark shades, value 2, chroma 4, forming a hue circle.

Table I

Average and Maximum Deviations of Screen Colour from Input CIE Specficiations

\begin{tabular}{|c|c|c|c|c|c|}
\hline \multicolumn{6}{|c|}{ Colours Showing the Largest Colour Difference in Each Group } \\
\hline & & $x$ & $y$ & $Y$ & $\begin{array}{c}\Delta E \\
\text { CMC } 2: 1\end{array}$ \\
\hline \multirow[t]{2}{*}{ Group 1} & Target & 0.313 & 0.329 & 1.12 & \\
\hline & Measured & 0.319 & 0.324 & 1.10 & 2.38 \\
\hline \multirow[t]{2}{*}{ Group 2} & Target & 0.374 & 0.325 & 59.1 & \\
\hline & Measured & 0.376 & 0.323 & 58.96 & 1.04 \\
\hline \multirow[t]{2}{*}{ Group 3} & Target & 0.293 & 0.249 & 19.77 & \\
\hline & Measured & 0.289 & 0.242 & 19.13 & 1.42 \\
\hline \multirow{2}{*}{ Group 4} & Target & 0.437 & 0.443 & 3.13 & \\
\hline & Measured & 0.434 & 0.435 & 3.21 & 1.64 \\
\hline \multicolumn{6}{|c|}{ Maximum and Average Deviations in Individual Co-ordinates for the Whole Set } \\
\hline & & $x$ & $y$ & $Y$ & \\
\hline \multirow{2}{*}{ Group 1} & Maximum & 0.006 & 0.005 & $2.91 \%$ & \\
\hline & Average & 0.001 & 0.002 & $0.94 \%$ & \\
\hline \multirow[t]{2}{*}{ Group 2} & Maximum & 0.004 & 0.003 & $0.94 \%$ & \\
\hline & Average & 0.002 & 0.003 & $0.53 \%$ & \\
\hline \multirow[t]{2}{*}{ Group 3} & Maximum & 0.005 & 0.007 & $3.26 \%$ & \\
\hline & Average & 0.002 & 0.003 & $1.10 \%$ & \\
\hline \multirow[t]{2}{*}{ Group 4} & Maximum & 0.006 & 0.008 & $4.70 \%$ & \\
\hline & Average & 0.003 & 0.004 & $3.27 \%$ & \\
\hline \multirow[t]{2}{*}{ Over-all } & Maximum & 0.006 & 0.008 & $4.70 \%$ & \\
\hline & Average & 0.002 & 0.003 & $1.46 \%$ & \\
\hline
\end{tabular}

Table I summarizes the average and maximum deviations from input $\mathrm{CIE}$ specifications of the measured screen specifications.

Table II (next page) shows the detail of the target and measured coordinates for the pale hue circle.

Table III shows the detail for the dark hue circle.

Although the three hue circles represent radically different mixing proportions from those at the neutral calibration points, it is clear that there is no fall-off in accuracy of prediction. This is found to be true right out to the gamut limit, where one or more of the gun values drop to zero. 
Table II

Measured and Target CIE Co-ordinates for Ten Pale Shades on the Calibrated Screen

\begin{tabular}{ccccccc}
\hline & Target Values & & & Measured Values & Difference \\
\hline$x$ & $y$ & $Y$ & $x$ & $y$ & $Y$ & CMC 2:1 \\
\hline 0.344 & 0.298 & 59.1 & 0.346 & 0.297 & 58.96 & 0.74 \\
0.374 & 0.325 & 59.1 & 0.376 & 0.323 & 58.96 & 1.04 \\
0.399 & 0.366 & 59.1 & 0.403 & 0.367 & 59.26 & 0.80 \\
0.391 & 0.412 & 59.1 & 0.393 & 0.414 & 59.66 & 0.56 \\
0.357 & 0.421 & 59.1 & 0.358 & 0.423 & 59.56 & 0.45 \\
0.282 & 0.370 & 59.1 & 0.281 & 0.371 & 59.56 & 0.48 \\
0.259 & 0.332 & 59.1 & 0.257 & 0.332 & 59.06 & 0.57 \\
0.246 & 0.289 & 59.1 & 0.244 & 0.286 & 58.57 & 0.94 \\
0.261 & 0.267 & 59.1 & 0.259 & 0.264 & 58.86 & 0.27 \\
0.296 & 0.270 & 59.1 & 0.295 & 0.267 & 58.67 & 0.84 \\
\hline
\end{tabular}

Table III

Measured and Target CIE Co-ordinates for Ten Dark Shades on the Calibrated Screen

\begin{tabular}{ccccccc}
\hline & Target Values & & & Measured Values & Differences \\
\hline$x$ & $y$ & $Y$ & $x$ & $y$ & $Y$ & CMC 2: 1 \\
\hline 0.356 & 0.260 & 3.13 & 0.356 & 0.252 & 2.98 & 1.34 \\
0.418 & 0.303 & 3.13 & 0.419 & 0.296 & 2.98 & 1.31 \\
0.467 & 0.374 & 3.13 & 0.473 & 0.374 & 3.08 & 0.55 \\
0.437 & 0.443 & 3.13 & 0.434 & 0.435 & 3.21 & 1.64 \\
0.358 & 0.465 & 3.13 & 0.361 & 0.467 & 3.27 & 0.70 \\
0.264 & 0.384 & 3.13 & 0.266 & 0.384 & 3.24 & 0.41 \\
0.223 & 0.315 & 3.13 & 0.228 & 0.317 & 3.25 & 0.66 \\
0.205 & 0.252 & 3.13 & 0.208 & 0.252 & 3.22 & 0.71 \\
0.226 & 0.219 & 3.13 & 0.224 & 0.217 & 3.16 & 0.35 \\
0.219 & 0.226 & 3.13 & 0.290 & 0.219 & 3.02 & 1.16 \\
\hline
\end{tabular}

\subsection{Applications}

It has been shown in extensive industrial trials that the above system of monitor calibration gives a very close visual-appearance match between the screen and textile samples with the same CIE co-ordinates.

The feedback-and-control system, known as the UMIST Adaptive Driver, has been built into a successful commercial CAD system for colour called Shademaster [9]. This is aimed at designers who create colour ideas. It can be regarded as a comprehensive colour atlas, allowing the visualization of millions of precisely defined colours. It also allows colours to be grouped, manipulated, and judged in combination, making the generation of colourways easier.

The system also has significant applications as a colour-communication tool. A colour definition can be faxed to a distant dyehouse and reproduced on any textile substrate, without the need for physical master patterns. The numerical data are fed into a local dye-recipe-formulation system instead of measured input from a spectrophotometer. It is also possible to view and judge visually how far 'off shade' a dye submission is, based on CIE co-ordinates transmitted back from the distant dyehouse. 
Shademaster has applications in technical colour management, where colour communication is important. Other applications include colour co-ordination across garment components and across colour ranges. Another feature is the ability to view and quantifty small colour differences.

This allows tolerance limits to be set up both visually and numerically.

\section{CONCLUSIONS}

We aim to show in this paper that a practical solution is available to the problem of controlling colour on a computer screen.

A measurement-and-feedback system is introduced which is flexible and accurate enough to handle both short- and long-term variations in monitor performance.

In order to reduce the calibration problem to manageable proportions, it is necessary to make assumptions of gun independence. It is also necessary to apply additive colour-mixing theory to reduce the number of RGB combinations used as calibration points.

An exhaustive calibration of all possible combinations would require 16.77 million measurements. We show that as few as twelve points may be used, without significantly sacrificing calibration accuracy.

Drive characteristics are modified dynamically in the system commercialized as the UMIST Adaptive Driver by maintaining three interrelated and balanced transfer functions. These functions ensure that $T$-unit quantities of $R, G$, and $B$ are mixed on the screen.

The transformation to gun-drive values from CIE co-ordinates is, in theory, exact. In practice, small deviations of screen colour occur owing to:

(i) variation of phosphor chromaticity with drive intensity;

(ii) breakdown of gun and/or screen-content independence;

(iii) inaccuracies due to interpolation between calibration points on the curves of Equation (1);

(iv) the use of finite steps (0-255) on the R, G, B scales.

In practice, the calibration has been found good enough to order prototype garments direct from screen colour, in the confident prediction that they will be a good visual match on delivery.

The colour-range management team of a major UK retailer have been using the system for over a year, and they now rely on screen visualization of colour as a method of shortening range-development lead times. 


\section{REFERENCES}

1 F.W. Billmeyer and M. Saltzman. 'Principles of Colour Technology', Wiley, New York, 2nd edition, 1981.

2 W.B. Cowan and N. Rowel. Col. Res. Appl., 1986, 11, Suppl., S34.

3 D.L. Post and C.S. Calhoun. Col. Res. Appl., 1989, 14, 172.

4 C.J. Hawkyard and D.P. Oulton. J. Soc. Dyers Col., 1991, 101, 309.

5 W.N. Sproson. 'Colour Science in Television and Display Systems', Hilger, Bristol, 1983.

6 W.D. Wright. 'The Measurement of Colour', Hilger, Bristol, 4th edition, 1969.

7 D.C. Rich. Text. Chem. Col., 1986, 18, No. 6, 16.

8 Computer-controlled imaging display, Barco Industries. Kortrijk, Belgium.

9 D.P. Oulton and C.J. Hawkyard. Spazio Tess., 1991. 5, June, 65 (English translation 83). 